\title{
Research on three - dimensional Cooperative Formation of Sea and Air for Cruise and Rescue
}

\author{
Fan Wei ${ }^{1}$ \\ ${ }^{1}$ School of Navigation, Wuhan University of Technology, Wuhan, China
}

\begin{abstract}
Aiming at the problems of maritime traffic safety, a new model of jointing USV and UAV for Three-dimensional cruise and rescue is studied. Using the Information Fusion Technology, through the leader-follower formation mode, The collaborative fleet remote control. At the same time, it discusses how to carry out effective supervision on the responsible sea area under the complicated and changing sea conditions, especially the quick and efficient completion of the maritime search and rescue mission.
\end{abstract}

\section{Introduction}

The role of the oceans as an important player in the world's economic activities is becoming increasingly important, the maritime traffic environment is more complex, highlighting a lot of maritime traffic safety problems. Therefore, the search and rescue of maritime cruise and distress accidents has also become the focus of maritime research in order to achieve "all-weather operation, all-round coverage, emergency rapid response" for the sea traffic safety management objectives [1-3].

Unmanned Surface Vessel (USV) is a kind of maritime intelligent sports platform capable of self-safe navigation under complex sea conditions, and has the characteristics of low cost, high efficiency and no casualties. Combined with unmanned aerial vehicles (UAV) widely used, the advantages of strong mobility, USV, UAV can cooperate with each other to form a convenient control of the formation of the formation of complex sea conditions in the face of cruise and rescue missions, the formation of cru ise and rescue Of the sea and air three-dimensional collaborative formation.

\section{Formation diversity}

\subsection{Formation pattern}

The determinants of formation include the nature and characteristics of the task, as well as the prevailing sea conditions and weather conditions.

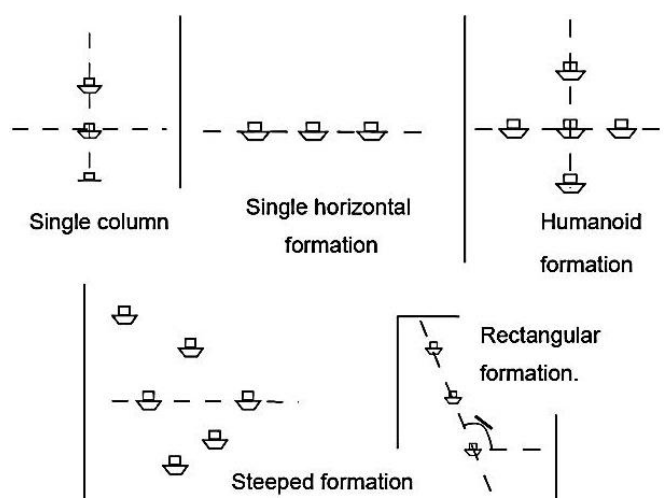

Figure 1. Formation

Table 1. Formation pattern classification

\begin{tabular}{|c|c|c|}
\hline $\begin{array}{c}\text { Formation } \\
\text { pattern }\end{array}$ & $\begin{array}{l}\text { Formation } \\
\text { elements }\end{array}$ & $\begin{array}{c}\text { Formation } \\
\text { characteristics }\end{array}$ \\
\hline Single column & $\beta=180^{\circ}, \alpha=0^{\circ}$ & $\begin{array}{l}\text { Formation is simple, } \\
\text { easy to maintain, more } \\
\text { flexible }\end{array}$ \\
\hline $\begin{array}{l}\text { Single } \\
\text { horizontal } \\
\text { formation }\end{array}$ & $\beta=90^{\circ}, \alpha=90^{\circ}$ & $\begin{array}{c}\text { Steering difficulties, } \\
\text { manipulation } \\
\text { inconvenience }\end{array}$ \\
\hline $\begin{array}{c}\text { Stepped } \\
\text { formation }\end{array}$ & $\beta \geq 90^{\circ}$ & $\begin{array}{l}\text { Better depth, Larger } \\
\text { width }\end{array}$ \\
\hline $\begin{array}{l}\text { Rectangular } \\
\text { formations }\end{array}$ & $\begin{array}{c}\beta=180^{\circ} \text { or } 90^{\circ} \\
\alpha=0^{\circ} \text { or } 90^{\circ}\end{array}$ & $\begin{array}{l}\text { Better depth, Large } \\
\text { width }\end{array}$ \\
\hline $\begin{array}{l}\text { Humanoid } \\
\text { formation }\end{array}$ & $\gamma 1=\gamma 2$ & $\begin{array}{l}\text { Good depth, Larger } \\
\text { width }\end{array}$ \\
\hline
\end{tabular}

\subsection{UAV in formation}

UAV's position in the formation is flexible, applicable to any USV formation mode. UAV has the characteristics of fast flight speed, strong maneuverability, wide monitoring 
range and long battery life. It can reduce the emergency response time of the formation, expand the effective area of the cruise and rescue, makes the function more Three-dimensional, makes up for the shortcomings of the USV formation, provides new regulatory perspectives.

\section{Cooperative control of formation}

\subsection{Information fusion technology}

The basis of control are communications, collaborative communication to form a specific network within formations, the members can achieve resource sharing. The information fusion technology will deal with the multi-source information of each sensor, combine the information according to certain optimization criteria, thus eliminate the possible redundant and contradictory data, and complement the information, reduce the uncertainty, and finally get the same complete conclusion, for the formation of decision-making to provide a strong guarantee .Includes Data conversion, Data related, Situation database, Fusion calculation [4].

\subsection{Centralized control mode}

Centralized control mode [5] is to use a higher configuration, better performance of the USV as a carrier, the carrier to complete the collaborative formation of the data analysis and processing, and sent to other members to carry out the task deployment. Here the centralized control system uses the leader - followed model [6]. The L-F model is shown in Fig.2:

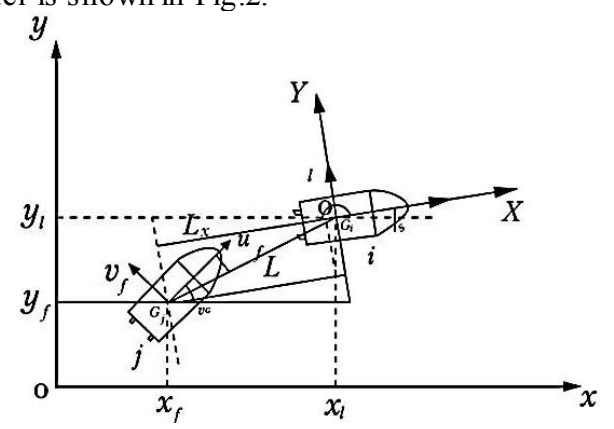

Figure 2. Leader - follower model

\subsection{Remote control system}

Remote control system [7-9] is divided into land-based control system and ship control system. The former mainly completes the real-time display of the status and velocity information of the USV and can send control commands to the ship-borne system. The latter can access the ship's position and velocity information, and can analyze the commands conveyed by the land-based control system and control the USV, including start up, turn, speed change, berthing, etc. In order to realize the positioning function of USV, adopts GPS positioning mode. GPS can not only determine the exact location but also calculate the speed of USVs. The land-based system uses the electronic chart system and establishes the GUI control system. The electronic chart can accurately display the real-time position of the USV. The GUI panel can send control commands to the ship borne system by setting different command buttons.

Land-based system access network, the ship-borne system access GPRS network, using the traditional Internet and GPRS wireless communication comb ination of the way through the TCP / IP protocol to achieve the two systems between the data communication function. USV use ultra- short wave communication for information exchange and task communication, also known as the use of 1 to 10 meters wavelength of electromagnetic waves for line-of-sight transmission. Ultra-shortwave wave shortwave wave propagation mode is highly stable, subject to seasonal and day and night changes in the small impact.

\section{The maritime cruise and rescue of formation}

Due to the limitations of the USV itself and its equipment and sensors, it is often difficult to complete a given task in a complex environment. But the formation of collaborative search tour can effectively overcome the restrictions, so the goal of a full range of search and observation. In short, USV, UAV collaborative formation makes the search system has better reconnaissance ability and higher fault tolerance, while reducing the waste of resources while improving the efficiency of search mission.

\subsection{Formation search mode}

The formation of the cooperative search mode [10] can be roughly divided into coverage mode and non-coverage mode. Coverage mode includes Extend Square mode, Parallel Line mode and Fan-shaped mode. Non-coverage mode includes Track mode.
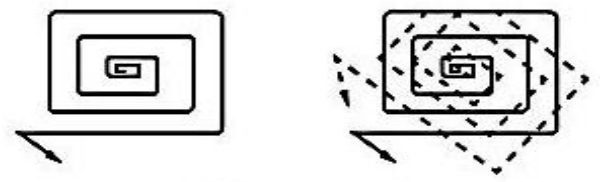

Extended square search

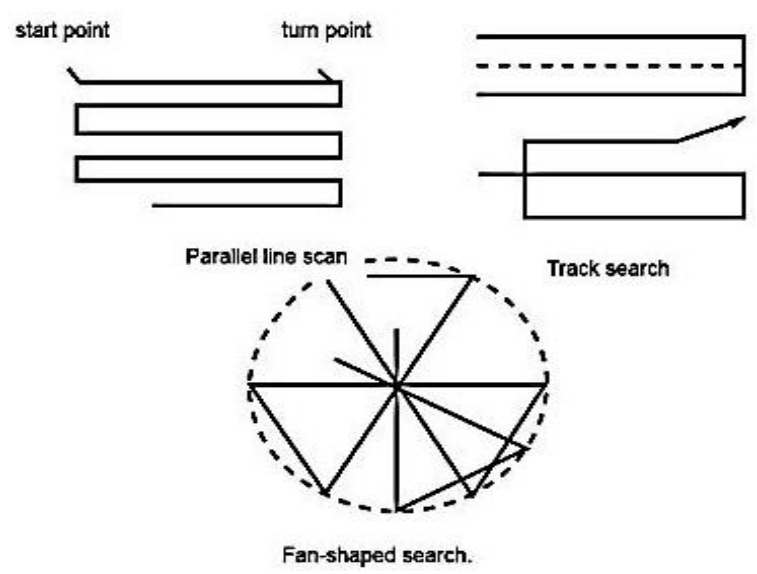

Figure 3. Formation search mode 
Parallel line scan search and rescue [11] is the most common, the calculation width is " $w$ ", USV speed is " $\mathrm{v}$ ", search area is "S". Assuming that the search area is rectangular, the target position is unknown, its probability is evenly distributed in the search area, and there is no coverage area, the search route function can be expressed as:

$$
\mathrm{b}(\mathrm{t})=\frac{W v t}{S},(t \geq 0)
$$

USVs do not find the target within time "t", and the probability of finding the target within the increment time " $\Delta \mathrm{t}$ " is $[1-\mathrm{b}(\mathrm{t})] w V \Delta t / S$, Whereby the probability that the USV finds the target at time " $\mathrm{t}+\Delta \mathrm{t}$ ":

$$
\begin{gathered}
\mathrm{b}(t+\Delta t)=b(t)+[1-b(t)] W V \Delta t / S \\
\text { By } \quad \text { the above } \quad b^{\prime}(t)=\operatorname{im}_{\Delta t \rightarrow 0} \frac{b(t+\Delta t)-b(t)}{\Delta t}=[1-b(t)]_{W V} / S \\
\text { B }(0)=0, \quad b(t)=1-e^{-t_{W V} / S},(t \geq 0)
\end{gathered}
$$

From the nature of the $b(t)$ function, the longer the formation search time, the slower the change in the probability of the target being found. When the search length " $\mathrm{v}$ " is close to " $\mathrm{S} / \mathrm{w}$ ", the probability of finding the target is close to "1". So for this search and rescue mode, should be selected perpendicular to the minimum span direction as USV search and rescue navigation direction, that is, the optimal path.

\subsection{Search and rescue equipment combination applications}

In the case of good visibility, the photoelectric tracking and monitoring equipment imaging system[12] [13] can clearly monitor the situation of the long distance sea surface with the maritime search lamp, and can effectively carry out the pollutant supervision and the night emergency rescue, Improve the success rate of finding targets (especially drowning man).

\subsection{Cruise and rescue in the UAV}

In the same distance, UAV's patrol radiation area is 12 times the USV [14], patrol effect is much better than the USV. Therefore, in the cruise and rescue process using UA V can effectively imp rove the cruise efficiency, rapid detection of regulatory waters within the latent risk factors. Through the machine, the ship can greatly enhance the flexibility of the formation of the task. UAV as the air flight platform [15], its control mode and

\begin{tabular}{|c|c|c|}
\hline $\begin{array}{l}\text { Maritime busi- } \\
\text { ness }\end{array}$ & UAV function & Functional description \\
\hline \multirow{3}{*}{ Daily cruise } & Regular cruise & $\begin{array}{l}\text { To inspect the waters and vessels in the area, and to supervise the traffic control areas, to } \\
\text { curb the sewage discharge }\end{array}$ \\
\hline & $\begin{array}{l}\text { Used as a VHF } \\
\text { aerial relay }\end{array}$ & $\begin{array}{l}\text { As the USV ship borne VHF and land-based communication distance is short, need } \\
\text { UAV equipped with VHF relay equipment, with the USV cruise }\end{array}$ \\
\hline & $\begin{array}{l}\text { With USV } \\
\text { supervision }\end{array}$ & $\begin{array}{l}\text { USV is slow at cruise, cannot be observed long-range unknown vessels, the use of ship } \\
\text { carrying UAV can expand the scope of reconnaissance }\end{array}$ \\
\hline \multirow{2}{*}{$\begin{array}{c}\text { Anti- } \\
\text { pollution } \\
\text { supervision }\end{array}$} & $\begin{array}{l}\text { Collect evidence of } \\
\text { pollution }\end{array}$ & $\begin{array}{l}\text { Use UAV for oil spills and chemical accident emergency evidence, reach the scene of } \\
\text { the accident will be real-time transmission to the control center }\end{array}$ \\
\hline & $\begin{array}{l}\text { Collect evidence of } \\
\text { dangerous accident }\end{array}$ & $\begin{array}{l}\text { UAV-USV joint investigation is required for marine hazardous sites, and UAV can } \\
\text { expand the survey area }\end{array}$ \\
\hline \multirow{4}{*}{$\begin{array}{l}\text { Emergency } \\
\text { search and rescue }\end{array}$} & Search targeting & $\begin{array}{l}\text { Borrow the UAV self-positioning system and airborne AIS to determine the location of } \\
\text { the accident, and the information back to the control center }\end{array}$ \\
\hline & $\begin{array}{l}\text { Video } \\
\text { transmission }\end{array}$ & $\begin{array}{l}\text { Through the video equipment to shoot the scene of the accident, the scene of the re- } \\
\text { al-time situation back to the land-based control center, easy to co-ordinate the command }\end{array}$ \\
\hline & Material delivery & $\begin{array}{l}\text { Through the UAV can complete the food, GPS buoys and small life-saving equipment } \\
\text { and other materials put }\end{array}$ \\
\hline & Act as a float & $\begin{array}{l}\text { UAV installed on the automatic inflatable equipment, set the location identification sig- } \\
\text { nal, if necessary, can fall into the sea as a life-saving buoy }\end{array}$ \\
\hline
\end{tabular}
formation function in the final analysis through its airborne system to complete the relevant equipment, include airborne digital camera, multi - spectral imager

Table 2. UAV maritime applications 


\section{Experimental verification}

\subsection{Design of the ship}

In order to verify the feasibility and robustness of the cooperative formation control system, the model ship experiment platform is used to verify. The experimental platform includes the leader system equipped with the leader ship, followed ship and UAV, for remote control of the computer. Results as shown:

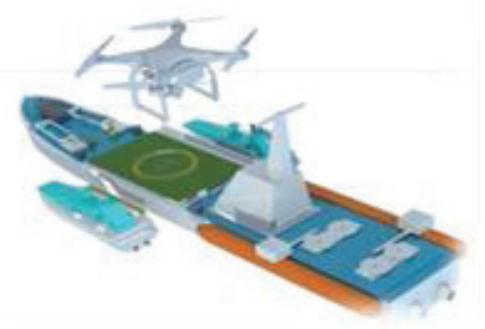

Figure 4. Model diagram

Microcontroller is control center. It can be written into the slave computer program, the program's role is to receive the instructions of the host computer, and code analysis, to understand what kind of action issued by the user.

\subsection{Algorithm design}

\subsubsection{Sports model}

First assume that the formation of the ith USV is the leader ship, the jth USV is followed ship, the formation of two ships composed of the leader- followed[16] model, as Fig 2 shown. Modeling the leader ship, definition: "L" is the relative distance between the followed ship and the leader ship; " $\Psi$ " is the relative angle between the followed ship and the leader ship; " $G$ " is the center point of the USV; " $\Phi \mathrm{f}$ " is the heading angle of the leader ship and the followed ship; Pl (x 1, y 1), Pf ( $\mathrm{x} \mathrm{f,} \mathrm{y} \mathrm{f)} \mathrm{are} \mathrm{the}$ coordinates of the position of the leader ship and the followed ship. The mathematical expression is:

$$
\begin{gathered}
\left\|\mathrm{L}_{y}-L_{y r}\right\| \leq \delta_{1} \\
\left\|\Psi-\Psi_{\mathrm{r}}\right\| \leq \delta_{2}
\end{gathered}
$$

Where " $\delta 1 "$ and " $\delta 2$ " are bounded positive numbers.

Define the tracking error of the heading angle:

$$
\mathrm{Z} \varphi=\varphi \mathrm{f}-\varphi \mathrm{l}
$$

Define the errors in the structure:

$$
\left\{\begin{array}{l}
\xi_{\mathrm{X}}=\mathrm{L}_{\mathrm{XR}}-\mathrm{L}_{\mathrm{X}} \\
\xi_{\mathrm{y}}=\mathrm{L}_{\mathrm{YR}}-\mathrm{L}_{\mathrm{Y}} \\
\xi_{\phi}=\phi_{\mathrm{f}}-\phi_{\mathrm{l}}
\end{array}\right.
$$

The kinematic model of USVs is:

$$
\left\{\begin{array}{c}
\mathrm{L}_{\mathrm{X}}=-\mathrm{u}_{\mathrm{l}}+\mathrm{u}_{\mathrm{f}} \cos \xi_{\phi}-\mathrm{v}_{\mathrm{f}} \sin \xi_{\phi}+\mathrm{L}_{\mathrm{rl}} \\
\mathrm{L}_{\mathrm{Y}}=-\mathrm{v}_{\mathrm{l}}+\mathrm{u}_{\mathrm{f}} \cos \xi_{\phi}+\mathrm{v}_{\mathrm{f}} \sin \xi_{\phi}+\mathrm{L}_{\mathrm{rl}} \\
\xi_{\phi}=\mathrm{r}_{\mathrm{f}}-\mathrm{r}_{\mathrm{l}}
\end{array}\right.
$$

Can be derived from the formation of the error system model:

$$
\left\{\begin{array}{c}
\xi_{\mathrm{x}}=-\mathrm{u} \cos \xi_{\phi}+\mathrm{v}_{\mathrm{r}} \sin \xi_{\phi}+\xi_{\mathrm{y}} \mathrm{r}_{\mathrm{i}}+\mathrm{u}_{\mathrm{i}}-\mathrm{L}_{\mathrm{R}} \psi_{\mathrm{R}} \sin \psi_{\mathrm{R}} \\
-\mathrm{L}_{\mathrm{R}} \mathrm{r}_{1} \sin \psi_{\mathrm{R}} \\
\xi_{\mathrm{x}}=-\mathrm{u} \sin \xi_{\phi}-\mathrm{v}_{\mathrm{r}} \cos \xi_{\phi}-\xi_{\mathrm{y}} \mathrm{r}_{\mathrm{i}}+\mathrm{v}_{\mathrm{i}}+\mathrm{L}_{\mathrm{R}} \psi_{\mathrm{R}} \cos \psi_{\mathrm{R}} \\
+\mathrm{L}_{\mathrm{R}} \mathrm{r}_{1} \cos \psi_{\mathrm{R}} \\
\xi_{\phi}=\mathrm{r}_{\mathrm{f}}-\mathrm{r}_{\mathrm{i}} \\
\mathrm{m}_{1} \mathrm{u}-\mathrm{m}_{2} \mathrm{vr}+\mathrm{d}_{1} \mathrm{u}=\tau_{1} \\
\mathrm{~m}_{2} \mathrm{v}-\mathrm{m}_{1} \mathrm{vr}+\mathrm{d}_{2} \mathrm{v}=0 \\
\mathrm{~m}_{3} \mathrm{u}+\left(\mathrm{m}_{2}-\mathrm{m}_{1}\right) \mathrm{ur}+\mathrm{d}_{3} \mathrm{r}=\tau
\end{array}\right.
$$

In the actual formation voyage, the distance $\mathrm{L}$ between USVs (measured by laser ranging) and the relative angle " $\Psi$ " (which can be calculated from the relative position) are calculated by comparing the actual distance "L" between the two ships angle " $\Psi$ " according to the external environment with in the allowable range of error within the allowable range can achieve the purpose of formation control, that is, to complete the formation, maintain, re-generation, formation to maintain the formation of obstacle avoidance and other tasks.

\subsubsection{Bow control}

During the process of ship moving horizontally, the hydrodynamic damping force is the main force, and the traverse velocity "V1"is bounded. Assuming that the interference is bounded:

$$
\begin{aligned}
& \left|W_{1}(t)\right| \leq w_{0} \\
& \left|W_{2}(t)\right| \leq w_{0} \\
& \left|W_{3}(t)\right| \leq w_{0}
\end{aligned}
$$


Design the controller to make the formation of the members of the track tracking error $\psi_{1} 、 \mu_{1} 、 Z_{1}$ final bounded.

The Define state variables " $\varphi_{i e}$ ", Using the filter to get its estimate:

$$
\varphi_{i e=} \psi_{1 \mathrm{e}+\gamma} \psi_{1 \mathrm{e}}
$$

(6) On both sides of the derivative get:

$$
\mathrm{m}_{i} \varphi_{i e}=f_{i 1}(x)-\tau_{i r}-W_{i \varphi}
$$

$f(\mathrm{x})$ for the unknown dynamic function, with the network to get its theoretical estimates:

$$
f(\mathrm{x})=\mathrm{W}_{\mathrm{i}}^{\mathrm{T}} \sigma\left(\mathrm{V}_{\mathrm{i}}^{\mathrm{T}} \xi_{\mathrm{i}}\right)+\varepsilon_{\mathrm{i}}
$$

To stabilize the system (7), we need to eliminate $f(\mathrm{x})$, so we use the adaptive term to approximate it:

$$
f(\mathrm{x})=\mathrm{W}_{\mathrm{i}}^{\mathrm{T}} \sigma\left(\mathrm{V}_{\mathrm{i}}^{\mathrm{T}} \xi_{\mathrm{i}}\right)
$$

The controller is:

$$
\begin{aligned}
& \tau_{\mathrm{ir}}=\left(k_{i 1}+h_{i 1}\right) \varphi_{i e}+W_{i}^{T} \sigma\left(V_{i}^{T} \xi_{i}\right) \\
& h_{i r}=k_{i 4}\left(\left\|\xi_{i} W_{i}^{T} \sigma^{\prime}\right\|_{F}^{2}+\left\|\sigma^{\prime} V_{i}^{T} \xi_{i}\right\|^{2}+1\right)
\end{aligned}
$$

Substituting control (10) into (7):

$$
\mathrm{m}_{33} \varphi_{i e}=-f(x)-\left(k_{i 1}+h_{i 1}\right) \varphi_{i e}-w_{i \varphi}
$$

Into the $\mathrm{f}(\mathrm{x})$ items, finishing to get:

$$
\begin{aligned}
& \mathrm{m}_{33 i} \varphi_{i e}=-W_{i 1}^{T}\left(\sigma-\sigma^{\prime} V_{i 1}^{T} \xi_{i 1}\right)-W_{i 1}^{T} \sigma^{\prime}\left(V_{i 1}^{T} \xi_{i 1}\right) \\
& +\varepsilon_{i 1}-\left(k_{i 1}+h_{i 1}\right) \varphi_{i e}-d_{i e}-W_{i \varphi}
\end{aligned}
$$

Longitudinal control and Bow control are similar.

\subsection{Experimental results}

According to the design idea of the formation, the L-F motion model of the bow control and longitudinal control of its experimental verification. In the remote control under the USV to follow the ideal path forward, control effect as shown:

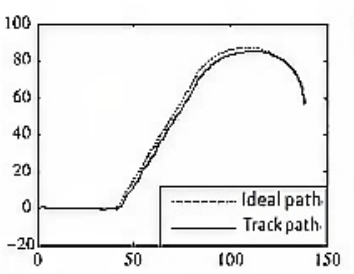

(a) Path image

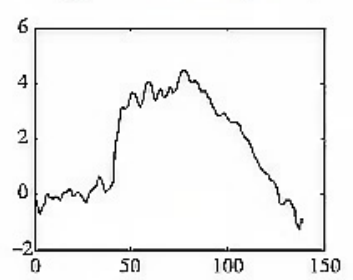

(c) Errorimage

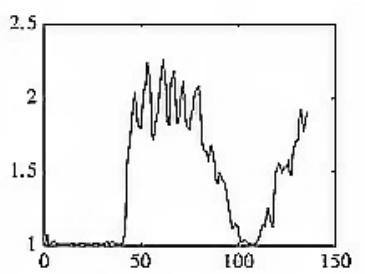

(b) Speed image

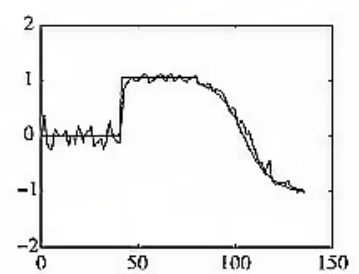

(d) Corner image
Figure 5. Control effect picture

Among them, a for the USV to track the ideal path forward curve, in considering the storm interference under the premise of USVs with good robustness, can follow the ideal path forward; Fig. $b$ for the tracking speed chart, In the process of unmanned sailing, the stability of the input speed, has been the right to follow the ideal path forward; Fig. $\mathrm{c}$ is the tracking error graph, the tracking error can be stabilized with in 4 unit distance, can be more accurately follow the ideal path forward; Fig. $\mathrm{d}$ is no progress; Fig. $\mathrm{d}$ is sailing steering angle, the USV straight sailing first and then turns at $60^{\circ}$ steering angle, and finally moves circumferentially along the $60^{\circ}$ direction.

In the L-F formation, the initial position of the three USVs is set to $(0,0),(0,10),(0,-10)$, the leader ships are experimentally designed to keep the speed of the ship at any time, fo llower ship at any time to adjust the speed of navigation, angular speed to follow the leader ship. While setting the safety distance $L=10$, in the navigation to ensure the safety of USV.

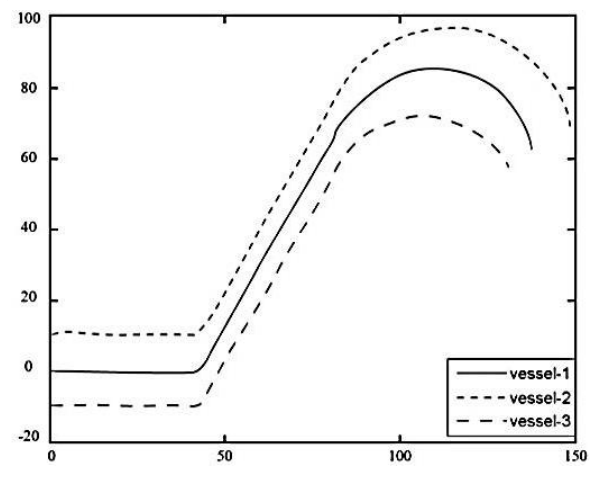

Figure 6. Rule formation effect chart 
Fig.9 shows the leader-followed formation in accordance with the ideal path of the experimental results, followership to keep in a safe distance within the sailing process can basically follow the route of the leadership, the error remains within the ideal range.

Set the initial coord inates of the leader ship $(0,0)$, the safety distance $\mathrm{L}=5$, the coordinate position of the two follower ships $(-10,10) 、(-10,-10)$, when the initial formation is irregular. The leader ship in the storm interference to do a straight line before the movement, followed by circular motion, asked follower ships to follow the leader ship, so that the formation to maintain stability.

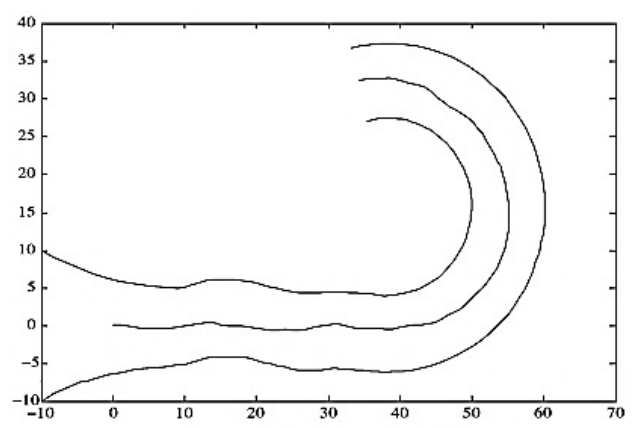

Figure 7. Irregular formation effect picture

Through the experimental results can be seen, the initial formation for the irregular state, after L-F control mode, the formation tends to be stable, the control effect is ideal.

\section{Conclusion}

The USV and UAV are coupled with each other to form a cooperative fleet for maritime cruise and rescue. Compared with the traditional formation mode, there is an unparalleled advantage in terms of supervision scope, search and rescue efficiency and real-time information.

The L-F model is used to control the USV and UAV cooperative formation, and the information fusion technology is applied to the cooperative information communication. The feasibility of the principle is verified by establishing the mathematical function.

Explores the various search and rescue modes in the process of maritime search and rescue, and emphasizes the role of UAV in maritime cruise.
The feasibility of the cooperative formation control is verified by the simulation test of the control platform and the shell. However, due to conditions, the UAV experimental link is relatively weak, should be further strengthened.

\section{References}

1. Kristina Dundović, Nilda Lazzo-Kurtin , Karlo Colić ,"The Role And The Importance Of The Maritime Rescue Coordination Centre", Journal of the Polytechnic of Rijeka (2015)

2. Ma Minglu "'Research on the Key Problems of Maritime Cruise Search and Rescue Integration", China Water Transport(2016)

3. Liu Li,Gu Qun,Peng Weiming,Deng Xiaoming, "Research on the System Framework of Maritime Stereoscopic Supervision System Based on Unmanned Aerial Vehicle", China Water Transport,ISSN: 1006-7973 (2014)

4. Wang Wei, "Research on Remote Control System of Unmanned Monitoring Ship", M.S. thes is, Zhe Jiang University (2014)

5. Jiang Feng,Xiao Jianmei,Wang Xihuai," 'Ship Formation Based on Generalized Predictive Control", Computer and Modernization,ISSN : 1006-2475(2014)

6. H.Niu.H.Oh, A. Tsourdos, "Development of Collision Avoidance Algorithms for the C-Enduro USV", IFAC Proceedings Volumes(2014)

7. Joseba Menoyo Larrazabal, Matilde Santos Peñas "Intelligent rudder control of an unmanned surface vessel”, Expert Systems With Applications(2016)

8. Cao Shijie,Zeng Fanming, Chen Yutao,"Method of Synchronous Control of Unmanned Surface Boat", Chinese Journal of Ship Research,ISSN : 1673-3185 (2015)

9. Gao Fei,"Design and Implementation of Software System for Unmanned Surface Boat Based on”,M.S. thesis, Ocean University of China (2015)

10. Yang Wangfeng,Yang Songlin, "Multi - unmanned cohort synergy strategy and search and rescue application", The 18th China International Boat \& Technology \& Equipment Exhibition \& High Performance Boat Symposium(2013) 
11. Chen yi, "A Preliminary Study on the Cooperative Strategy Based on Optimization and Its Realization”,M.S. thesis,Jiangsu University Of Sc ience And Technology (2016)

12. Keller, John, "Northrop Grumman to provide BAMS maritime surveillance UAV with ability to sense and avoid other aircraft", Military \& Aerospace Electronics (2011)

13. Lin Jianhui, "Photoelectric tracking and monitoring, satellite communications, maritime search lights and other equipment in the maritime cruise search and rescue combination of applications", Ship Commu- nication and Navigation Proceedings.

TN915.85(2009)

14. Anonymous, "RESPEKT: The German Maritime Search and Rescue Service at 150", Ausmarine (2015)

15. Wei Lei,Li Yunbin, "Research on the Optimization of Maritime Cruise Path of Unmanned Aerial Vehicle",Tian Jin navigation(2015)

16. Shen DongBin, Sun ZhenDong, Sun WeiJie, Leader-follower formation without leader's velocity information ,Science Chine(Information Sciences, 2014) 